Revista Universo Contábil, ISSN 1809-3337

FURB, v. 7, n.1, p. 49-67, jan./mar., 2011

doi:10.4270/ruc.2011104

Disponível em www.furb.br/universocontabil

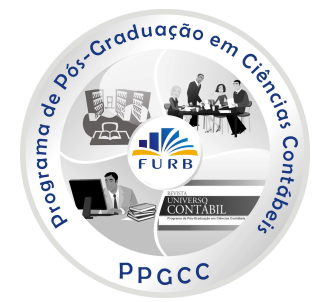

\title{
A INFLUÊNCIA DA GOVERNANÇA CORPORATIVA NO DESEMPENHO E NA ESTRUTURA DE CAPITAL DAS EMPRESAS LISTADAS NA BOVESPA ${ }^{1}$ \\ THE INFLUENCE OF CORPORATE GOVERNANCE IN PERFORMANCE AND CAPITAL STRUCTURE OF COMPANIES LISTED IN BOVESPA
}

\author{
Kelmara Mendes Vieira \\ Doutora em Administração na Universidade Federal do Rio Grande do Sul \\ Professora do Programa de Pós-Graduação em Administração da \\ Universidade Federal de Santa Maria \\ Endereço: Rua Floriano Peixoto, Prédio da Ex-Reitoria, 5ำ andar \\ CEP: 97015-372 - Santa Maria/RS - Brasil \\ Email: kelmara@smail.ufsm.br \\ Telefone: (55) 32209297 \\ Maria Dolores Pohlmann Velasquez \\ Mestre em Administração na Universidade Federal de Santa Maria \\ Endereço: Rua dos Andradas, 1416 \\ CEP: 97010-032 - Santa Maria/RS - Brasil \\ Email: mdolores@smail.ufsm.br \\ Telefone: (55) 3025-9010 \\ Vanderléia Leal Losekann \\ Mestre em Administração na Universidade Federal de Santa Maria \\ Endereço: Rua Marechal Floriano, 1184 \\ CEP: 97015-000 - Santa Maria/RS - Brasil \\ Email:wandeka@smail.ufsm.br \\ Telefone: (55) 3220-4575 \\ Paulo Sérgio Ceretta \\ Doutor em Engenharia de Produção na Universidade Federal de Santa Catarina \\ Professor do Programa de Pós-Graduação em Administração da \\ Universidade Federal de Santa Maria \\ Endereço: Rua Floriano Peixoto, Prédio da Ex-Reitoria, 5o andar \\ CEP: $97015-372$ - Santa Maria/RS - Brasil \\ Email: ceretta@smail.ufsm.br \\ Telefone: (55) 3220-9297
}

\section{RESUMO}

1 Artigo recebido em 08.04.2009. Revisado por pares em 26.01.2010. Reformulado em 22.06.2010. Recomendado para publicação em 30.06.2010 por Ilse Maria Beuren (Editora). Publicado em 31.03.2011. Organização responsável pelo periódico: FURB. 
A governança corporativa relaciona-se à gestão de uma organização e torna-se alvo de interesse dos empresários quando percebem que suas práticas contribuem para resolver conflitos de interesses entre diretores e acionistas. Este estudo objetiva avaliar se a adoção de práticas de governança corporativa altera a estrutura de capital e o desempenho das empresas. A amostra totaliza 84 empresas possuidoras de ações negociadas na BOVESPA e listadas no N1, N2 e NM. A pesquisa utiliza testes de diferenças com vistas à identificar alterações de estrutura e desempenho e aplica a regressão em painel com o propósito de avaliar se a governança corporativa influencia as variações na estrutura de capital e no desempenho das empresas. As variáveis independentes são dadas pelo índice de governança, percentual de ações ordinárias do acionista controlador, percentual de ações ordinárias do maior acionista, percentual de ações ordinárias dos cinco maiores acionistas e pela independência do conselho. As variáveis dependentes são o retorno sobre o patrimônio líquido, o retorno das ações e o endividamento geral. O resultado mostrou pouca influência exercida pelas variáveis independentes na variável dependente, logo não se pode inferir que as práticas de governança corporativa adotadas pelas empresas que ingressaram no N1, N2 e NM tenham contribuído expressivamente para as variações no desempenho e na estrutura de capital das empresas, pelo menos nos limites dessa amostra.

Palavras-chave: Governança. Desempenho. Estrutura.

\section{ABSTRACT}

The corporate governance relates to the management of an organization and becomes the target of interest of entrepreneurs when they realize that their practices contribute to solve conflicts of interests between directors and shareholders. This study aims to evaluate whether the adoption of corporate governance practices changes the capital structure and the companies' performance. The sample totalizes 84 companies holders of shares negotiated in BOVESPA and listed in the N1, N2 and NM. The research uses tests of differences to identify changes in structure and performance, and apply panel data regression with the purpose of assessing whether corporate governance influences variations in capital structure and the companies' performance. The independent variables are given by the index of governance, percentage of ordinary shares of the controlling shareholder, percentage of shares of the majority shareholder, the percentage of ordinary shares of the five majority shareholders and the independence of the board. The dependent variables include the equity return, stock return and general indebtedness. The result showed a little influence exercised by the independent variables in the dependent variable, thus it cannot be inferred that the corporate governance practices adopted by the companies that joined in N1, N2 and NM have contributed expressively to variations in the performance and the capital structure of the companies, at least within the limits of this sample.

Keywords: Governance. Performance. Structure.

\section{INTRODUÇÃO}

A abertura de novas formas de financiamento traz à tona questões relacionadas com a estrutura de capital, principalmente no sentido de buscar a melhor decisão de financiamento, e altera a forma de atuação da gestão da empresa, na medida em que passa a ser responsável pelo relacionamento com os investidores. Visando a minimização dos conflitos de interesses, algumas empresas optam pela adoção de práticas de governança corporativa como um meio de harmonizar a relação entre acionistas e gestores, proporcionando aos primeiros uma maior 
igualdade de direitos e proteção.

O trinômio governança corporativa, estrutura de capital e desempenho insere-se no espaço empresarial e acadêmico como base para a formação de um conjunto de procedimentos e regulamentos que permite aos acionistas um melhor acompanhamento da gestão. Tal mecanismo de controle permite sintonia entre os acionistas e seus contratados, cuja forma de atuação caracteriza-se pela governança corporativa. Desse modo, as práticas e os relacionamentos entre acionistas/cotistas, conselho de administração, diretoria, auditoria independente e conselho fiscal objetivam otimizar o desempenho da empresa, facilitando o acesso ao capital (BOVESPA, 2007).

A adoção de melhores práticas de governança corporativa contribui tanto para a otimização do desempenho empresarial quanto para o desempenho no mercado de capitais. $\mathrm{O}$ desempenho empresarial, também conhecido como resultado financeiro e obtido com base nas informações contábeis, serve para avaliar a situação econômica e financeira da empresa. Dentre seus principais indicadores, tem-se o giro do ativo, margem líquida, rentabilidade do ativo (ROA) e a rentabilidade do patrimônio líquido (ROE). O desempenho de mercado, direcionado ao mercado de ações refere-se à maior facilidade para obtenção de recursos, maior liquidez e menor custo.

A rentabilidade, uma das medidas de desempenho, é responsável pela sobrevivência das empresas e exerce grande influência nas decisões gerenciais. Para Silva e Moraes (2006), quanto maior a rentabilidade, menor o nível de substituição dos executivos, o que leva a considerar que uma estrutura de governança satisfatória conduz à melhoria da performance empresarial. O desempenho e a estrutura de capital de uma empresa encontram-se relacionados quando se admite que uma firma rentável e adequadamente administrada não terá problemas de solvência ou de capacidade de pagamento, pois uma liquidez ruim decorre, provavelmente, de uma inadequada rentabilidade passada ou mau redirecionamento de seus lucros (PAVODESE; BENEDICTO, 2005).

Partindo da hipótese de que as práticas de governança corporativa afetam o desempenho das empresas e que o desenvolvimento do mercado de capitais está diretamente ligado a uma boa política de governança, os níveis de governança da BOVESPA são uma alternativa. Implantados em dezembro de 2000 pela Bolsa de Valores de São Paulo (BOVESPA), o Novo Mercado e os níveis diferenciados de governança corporativa (Nível 1 e Nível 2) são segmentos especiais de listagem, desenvolvidos com o objetivo de proporcionar um ambiente de negociação que estimule o interesse dos investidores e a valorização das companhias.

Esta pesquisa objetiva identificar a influência da governança na estrutura de capital e no desempenho das empresas que ingressaram nos níveis de governança. Assim, através da análise da estrutura de capital e do desempenho das empresas listadas nos níveis diferenciados da BOVESPA, investiga-se a relação entre os elementos operacionais, econômicos e financeiros com vistas à responder a seguinte questão de pesquisa: A adoção das práticas de governança corporativa afeta a estrutura de capital e o desempenho das companhias?

\section{REVISÃO DA LITERATURA}

Apesar de ter ocorrido mais intensamente a partir da década de 80 nos Estados Unidos, a origem do desenvolvimento da governança corporativa remonta aos idos de 1930, quando Berle e Means já cogitavam a importância de separar a propriedade do controle. No Brasil, as discussões se intensificaram a partir 1990, tornando-se objeto de pesquisas acadêmicas sob os mais diversos enfoques, bases teóricas, conceitos, utilização de suas práticas e características. A governança tornou-se alvo de interesse das organizações quando os empresários se deram conta que suas práticas poderiam contribuir para resolver as divergências entre os diretores e acionistas, geradas pela diluição da propriedade das ações. Carlsson (2001), ao comentar a 
pertinência e importância do tema, considerou o século XIX como o período dos empreendedores, o século XX como a época do gerenciamento e o século XXI como o que deu vez à governança corporativa.

A governança corporativa vincula-se aos princípios da eqüidade, transparência, ética, dever de prestar contas e obediências às leis, os quais regem as decisões da empresa. Pode ser definida como um sistema mediante o qual as empresas são dirigidas e controladas, tendo o conselho de administração como ponto essencial. O papel do conselho de administração na governança corporativa é destacado por ocasião do processo decisório da gestão, da ratificação das informações relevantes e no monitoramento da alta gestão, consideradas decisões de controle. As etapas de iniciação e de implementação pertencem às decisões de gestão (diretoria executiva) e tal separação é necessária para garantir que determinada decisão não seja exercida por um agente que atue, ao mesmo tempo, como gestor e controlador (FAMA; JENSEN, 1983). Nas companhias que possuem propriedade e controle separados, as decisões de controle são transferidas a outros agentes (conselho de administração), o que, de certa forma, garante a sobrevivência eficaz da corporação.

O conceito de governança corporativa sob a ótica econômico-financeira foi proposto por Shleifer e Vishny (1997) ao comentarem sobre as relações de agência. Os investidores sentem-se protegidos com relação ao retorno de suas aplicações quando a prática da governança corporativa é adotada nas empresas. Tanto os credores, como os acionistas, possuem maior disposição em aplicar seus recursos nas organizações preocupadas em proteger seus direitos contra a expropriação dos controladores. Contudo, os mecanismos de governança corporativa diferem entre os países. Nos Estados Unidos e Reino Unido o controle acionário é pulverizado, em conseqüência, o conflito ocorre entre acionistas e a administração das empresas, o que exige uma proteção legal mais eficiente. Esses dois fatores, proteção legal e certo grau de propriedade concentrada, são elementos essenciais de um bom sistema de governança corporativa.

Em contraste, no Brasil, a forma concentrada do controle acionário, contribui para o principal conflito de agência existente no país, ou seja, entre acionistas minoritários e acionistas majoritários (DAMI; ROGERS; RIBEIRO, 2007). Assim, como exemplo de políticas mais rígidas de governança corporativa, a criação dos níveis de governança surgiu com vistas a negociar papéis das empresas que adotassem melhores regras de proteção aos acionistas minoritários e também que fossem transparentes em suas contas. Para tanto, a BOVESPA criou o Novo Mercado (NM) e os níveis diferenciados de governança corporativa, Nível 1 (N1) e Nível 2 (N2). O Quadro 1 apresenta um quadro-resumo dos níveis de governança da BOVESPA.

\begin{tabular}{|l|l|l|l|}
\hline Característica/nível & \multicolumn{1}{|c|}{ Nível 1 } & \multicolumn{1}{c|}{ Nível 2 } & \multicolumn{1}{c|}{ Novo mercado } \\
\hline $\begin{array}{l}\text { \% mínimo de ações em circulação } \\
\text { (free float) }\end{array}$ & \multicolumn{1}{|c|}{$25 \%$} & \multicolumn{1}{c|}{$25 \%$} \\
\hline Características das ações emitidas & $\begin{array}{l}\text { Permite a existência } \\
\text { de ações ON e PN }\end{array}$ & $\begin{array}{l}\text { Ações ON e PN (com } \\
\text { direitos adicionais) }\end{array}$ & $\begin{array}{l}\text { Somente de ações } \\
\text { ON }\end{array}$ \\
\hline Conselho de administração & $\begin{array}{l}\text { Mínimo de } \\
3 \text { membros } \\
\text { (conforme } \\
\text { legislação) }\end{array}$ & $\begin{array}{l}\text { Mínimo de cinco } \\
\text { membros: } 20 \% \\
\text { devem ser } \\
\text { independentes }\end{array}$ & $\begin{array}{l}\text { Mínimo de cinco } \\
\text { membros: } 20 \% \\
\text { devem ser } \\
\text { independentes }\end{array}$ \\
\hline $\begin{array}{l}\text { Demonstrações financeiras anuais } \\
\text { em padrão internacionais }\end{array}$ & Facultativo & US GAAP ou IFRS & US GAAP ou IFRS \\
\hline Concessão de tag along & $\begin{array}{l}80 \% \text { para ações ON } \\
\text { (conforme } \\
\text { legislação) }\end{array}$ & $\begin{array}{l}100 \% \text { para ações ON } \\
\text { e 80\% para ações PN }\end{array}$ & $100 \%$ para ações ON \\
\hline Adoção da câmara de arbitragem & Facultativo & Obrigatório & Obrigatório \\
\hline
\end{tabular}

Quadro 1 - Comparativo dos níveis de governança da BOVESPA 


\subsection{Governança corporativa, estrutura de capital e desempenho}

Devido a sua amplitude, a governança corporativa pode ser aplicada nas mais diversas áreas. No caso específico desta pesquisa, a conjugação da estrutura de capital e desempenho representa a oportunidade de se estudar o assunto governança corporativa focado na contabilidade. Para Sloan (2001), embora a ciência contábil seja fundamental em estudos de governança corporativa, as pesquisas na área poderiam ser mais exploradas, já que, a maior parte da produção acadêmica refere-se à economia e finanças. $\mathrm{O}$ fruto de sua pesquisa destaca o trabalho de Bushman e Smith (2001), que posicionam a contabilidade, através da divulgação de relatórios, como meio de promoção da governança coporativa nas organizações. Evidenciam que as informações contidas nos relatórios minimizam os conflitos de agência, pois servem de referência para a tomada de decisão.

A escassez de recursos e o elevado custo dos financiamentos fazem crescer a importância da rentabilidade e estrutura de capital no campo das finanças, na medida em que contribuem para o equilíbrio econômico-financeiro da empresa. Para Catapan e Catapan (2006), a eficácia na aplicação dos recursos está condicionada harmonicamente aos valores recebidos (recursos próprios), aos financiamentos externos (recursos de terceiros) e aos reforços de capital efetuados pelos acionistas. O equilíbrio dessa equação proporciona uma organização sustentável e abre caminho para o desenvolvimento da governança corporativa.

A estrutura de capital, segundo Ross, Westerfield e Jaffe (2007), representada pelas proporções do financiamento da empresa com capital de terceiros e capital próprio, pode ser definida como o conjunto dos títulos usados para financiar as atividades empresariais. As fontes de financiamento, representadas no lado do passivo do balanço patrimonial, envolvem os recursos de terceiros de curto prazo (passivo circulante), recursos de terceiros de longo prazo (passivo exigível a longo prazo) e recursos próprios de longo prazo (patrimônio líquido). Entretanto, no aspecto prático, o quociente entre capital de terceiros e próprio envolve uma combinação de impostos com custos de capital de terceiros, não existindo, contudo, uma fórmula exata, disponível para determinar uma estrutura ótima de capital (ROSS; WESTERFIELD; JAFFE, 2007). Assim, as investigações sobre a escolha da estrutura de financiamento por parte das empresas ganham espaço.

Com relação ao desempenho, a academia vem tentando identificar fatores determinantes que efetivamente levam as empresas a aumentarem seus rendimentos. A governança corporativa sob o aspecto dos direitos dos acionistas e sua relação com o desempenho das empresas foi investigada por Gompers, Ishii e Metrick (2003). Ao estabelecerem um índice de governança como fator de equilíbrio entre os acionistas e os gestores, os autores concluíram que a governança relaciona-se de forma significativa com o valor da firma ( $Q$ de Tobin), ou seja, empresas cujos acionistas possuem direitos fortes apresentam melhor desempenho e maior valor de mercado.

Em pesquisa mais recente, Galdi e Menezes (2008) investigaram a relação entre valor e desempenho (variáveis dependentes) e a estrutura de propriedade e qualidade da governança corporativa (variáveis independentes) em empresas brasileiras, não financeiras e negociadas na BOVESPA no período 2003-2008. O valor da firma e $Q$ de Tobin compuseram as variáveis de valor enquanto que as variáveis de desempenho foram dadas a partir de indicadores contábeis, como lucro operacional e lucro antes dos juros, impostos, depreciações e amortizações. Na estrutura de propriedade foram consideradas as variáveis de concentração das ações dos maiores acionistas e como indicadores de qualidade da governança corporativa atribuiram variáveis dummies para indicar se a empresa pertence ou não aos níveis de governança. Considerando que as variáveis dependentes podem sofrer alterações por fatores que, se não forem controlados podem alterar os resultados, utilizaram como variáveis de controle a estrutura de capital, tamanho da empresa, liquidez em bolsa e emissão de ADR.

O modelo adotado constituiu de um agrupamento de dados em painel desequilibrado, 
os quais foram testados pelos métodos dos mínimos quadrados ordinários (MQO) com abordagem Pooled. Os autores concluíram que existe uma relação positiva entre valor e concentração de ações ordinárias e totais do maior acionista até certa faixa. Em concentrações mais elevadas, esta relação é negativa. Quando se analisa o desempenho, a relação é linear e positiva. Os resultados sinalisam ainda que a adoção de boas práticas pode refletir de forma positiva no valor da empresa e negativamente no desempenho, especialmente nas empresas listadas no Novo Mercado.

Juntamente com o endividamento, o conhecimento do retorno sobre os ativos, investimentos, patrimônio líquido e a rentabilidade das vendas proporcionam melhor avaliação do desempenho organizacional. As decisões que envolvem os custos da origem dos recursos (passivo) e os retornos de sua aplicação (ativos) devem ser discutidas de maneira integrada, pois o volume dos investimentos depende das condições de financiamento. A decisão de empréstimos em curto prazo, por exemplo, cujo destino seja financiar bens do ativo permanente, sinaliza instabilidade financeira, uma vez que será necessária a renovação da dívida circulante com vistas a manter o investimento realizado em longo prazo.

Tais procedimentos conduzem à reflexão sobre as práticas da governança corporativa, considerando que o retorno dos investimentos realizados deve, no mínimo, satisfazer as expectativas de remuneração dos proprietários do capital (credores e acionistas), de forma a viabilizar economicamente a empresa (ASSAF NETO, 2000). O investimento em um negócio em detrimento de outro, com risco equivalente, gera o custo de oportunidade, que tanto o acionista como o credor esperam recuperar (COPELAND; KOLLER; MURRIN, 2000).

Partindo da hipótese de que as práticas de governança corporativa afetam o desempenho das empresas e que o desenvolvimento do mercado de capitais está diretamente ligado a uma boa política de governança, os níveis de governança surgem como formas alternativas no sentido de garantir os direitos dos minoritários.

O Quadro 2 apresenta uma síntese das relações, as variáveis utilizadas e os resultados obtidos nos estudos sobre governança.

\begin{tabular}{|c|c|c|c|}
\hline Relação & Variáveis & Resultados & Autores \\
\hline $\begin{array}{l}\text { Controle acionário e } \\
\text { estrutura de capital }\end{array}$ & $\begin{array}{l}\text { Controle acionário, } \\
\text { endividamento }\end{array}$ & $\begin{array}{l}\text { Maior concentração acionária, } \\
\text { menor endividamento. }\end{array}$ & $\begin{array}{l}\text { Procianoy e } \\
\text { Schnorrenberg } \\
\text { (2002). }\end{array}$ \\
\hline $\begin{array}{l}\text { Concentração } \\
\text { acionária e } \\
\text { desempenho }\end{array}$ & $\begin{array}{l}\text { Controle acionário, } \\
\text { rentabilidade do patrimônio } \\
\text { líquido, receita líquida, } Q \text { de } \\
\text { Tobin }\end{array}$ & $\begin{array}{l}\text { Não há relação entre o grau de } \\
\text { concentração e o desempenho } \\
\text { e estrutura de capital. Há } \\
\text { relação entre a concentração } \\
\text { de propriedade e a receita } \\
\text { líquida. }\end{array}$ & $\begin{array}{l}\text { Dami, Rogers e } \\
\text { Ribeiro (2007). }\end{array}$ \\
\hline \multirow[t]{3}{*}{$\begin{array}{l}\text { Governança e } \\
\text { desempenho }\end{array}$} & $\begin{array}{l}\text { Índices de liquidez, } \\
\text { endividamento, rentabilidade, } \\
\text { valor médio mensal das ações } \\
\text { negociadas, volume de } \\
\text { recursos financeiros }\end{array}$ & $\begin{array}{l}\text { Das três unidades estudadas, } \\
\text { apenas uma confirma que a } \\
\text { adesão ao nível de governança } \\
\text { melhora o desempenho. }\end{array}$ & $\begin{array}{l}\text { Dalfor, Oliveira e } \\
\text { Souza (2007). }\end{array}$ \\
\hline & Liquidez das ações & $\begin{array}{l}\text { A adesão aos níveis de } \\
\text { governança tem impacto } \\
\text { positivo na liquidez. }\end{array}$ & $\begin{array}{l}\text { Martins, Silva e } \\
\text { Nardi (2006). }\end{array}$ \\
\hline & $\begin{array}{l}\text { Preço, volume, liquidez, } \\
\text { volatilidade das ações }\end{array}$ & $\begin{array}{l}\text { As adoções das práticas de } \\
\text { governança têm impacto } \\
\text { positivo na valoração das } \\
\text { ações, no volume negociado e } \\
\text { na liquidez. }\end{array}$ & Carvalho (2002). \\
\hline
\end{tabular}




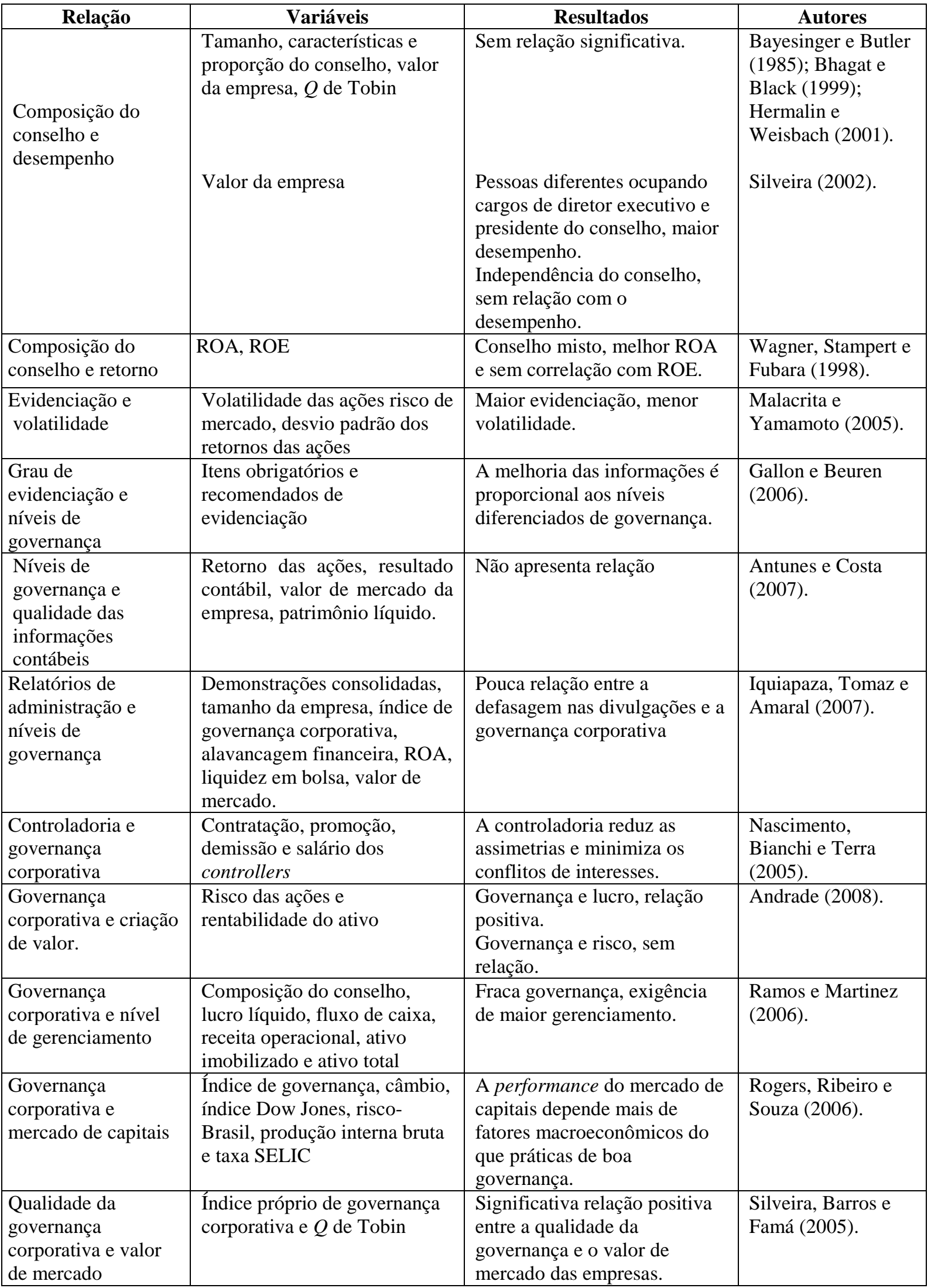

Quadro 2 - Relações avaliadas e resultados obtidos nos estudos de governança corporativa

\section{ASPECTOS METODOLÓGICOS}

Para a seleção da amostra foram consideradas as empresas registradas como sociedade 
anônima de capital aberto, possuidoras de ações negociadas na BOVESPA, com dados disponíveis no Economática e que ingressaram nos níveis de governança até 31 de dezembro de 2006. Do total de 86 empresas, foram excluídas as empresas Suzano Papel e Light S.A., devido à incorporação da primeira em outra empresa não pertencente aos níveis de governança e à reestruturação societária da segunda, ficando a amostra, no intervalo de $2001 \mathrm{a}$ 2006, com um total de 84 empresas.

A escolha das variáveis deu-se com base em relevantes pesquisas publicadas em nível nacional e internacional, as quais testaram a governança corporativa aliada ao desempenho e estrutura de capital das empresas. Com vistas à condensar a mensuração das variáveis, optouse pela construção de um índice capaz de englobar as práticas de governança adotadas pelas empresas integrantes da amostra.

Assim, o índice de governança constante do Quadro 3 foi calculado considerando-se as variáveis: big five, tipo de controlador, presença de acordo dos acionistas, unificação dos cargos, tipo de parecer, emissão de debêntures, reinvestimento de lucros e distribuição de dividendos, negócios sociais, investimentos em controladas e/ou coligadas, descrição dos negócios, comentários sobre a conjuntura econômica, recursos humanos, investimentos realizados e a realizar, pesquisa e desenvolvimento, novos produtos e serviços, meio ambiente, reformulações administrativas, direitos dos acionistas, perspectivas futuras, balanço social, fluxo de caixa, valor adicionado e auditores independentes em consultoria. Tal índice foi construído a partir da divisão da soma das variáveis dummys por 23, sendo o resultado da divisão multiplicado por 100. Desse modo, a empresa que apresentasse todas essas variáveis teria o valor do índice igual a 100.

Para medir o relacionamento entre governança corporativa, estrutura de capital e desempenho das empresas consideradas na amostra a literatura apresenta um número amplo de variáveis. Dentre as variáveis sugeridas pela literatura sintetisads no Quadro 2 buscou-se aliar os objetivos da pesquisa com a possibilidade de se conseguir os respectivos dados. Assim, definem-se as variáveis de governança, desempenho empresarial, desempenho de mercado e estrutura de capital apresentadas no Quadro 3.

\begin{tabular}{|c|c|}
\hline Variáveis & Medida \\
\hline Governança corporativa & \multirow{3}{*}{$\begin{array}{l}\mathrm{IG}=(\mathrm{VD}(1)+\mathrm{VD}(2)+\ldots+\mathrm{VD}(23)) / 23 \text { onde: } \\
\mathrm{VD}(i)=\text { variável } d u m m y \text { das variáveis formadoras do índice, com } i= \\
1, \ldots, 23 \\
\text { Representatividade do maior acionista da empresa }\end{array}$} \\
\hline Índice de governança & \\
\hline $\begin{array}{l}\% \text { de ações ordinárias do maior } \\
\text { acionista }\end{array}$ & \\
\hline $\begin{array}{l}\% \text { de ações ordinárias dos cinco } \\
\text { maiores acionistas }\end{array}$ & Representatividade dos 5 maiores acionistas da empresa \\
\hline $\begin{array}{l}\% \text { de ações ordinárias do acionista } \\
\text { controlador }\end{array}$ & \\
\hline \multirow[t]{4}{*}{ Independência do conselho } & Ext Int \\
\hline & $\overline{\text { Tot }}-\overline{\text { Tot }}$, onde: \\
\hline & Tot $=\mathrm{n}$. total e membros do conselho \\
\hline & $\begin{array}{l}\text { Ext }=\text { n. de membros não executivos } \\
\text { Int }=\text { n. de membros executivos }\end{array}$ \\
\hline Desempenho empresarial & \multirow{8}{*}{$\begin{array}{l}\text { ativo circulante + realizável a LP/passivo circ. + passivo exig. a LP } \\
\text { ativo circulante/passivo circulante } \\
\text { lucro líquido/patrimônio líquido } \\
\text { lucro operacional/ativo total } \\
\text { lucro líquido após o imposto de renda/ativo total } \\
\text { lucro operacional Ebitida/ativo total } \\
\text { valor da empresa/ativo total }\end{array}$} \\
\hline Liquidez geral & \\
\hline Liquidez corrente & \\
\hline ROE & \\
\hline ROA & \\
\hline Margem líquida & \\
\hline Ebitida & \\
\hline Q de Tobin & \\
\hline
\end{tabular}




\begin{tabular}{|c|c|}
\hline Variáveis & Medida \\
\hline Desempenho de mercado & \multirow{9}{*}{$\begin{array}{l}\text { lucro/quantidade total de ações } \\
L Q=100 \times\left(\frac{p}{P}\right) \times \sqrt{\left(\frac{n}{N}\right) \times\left(\frac{v}{V}\right)} \\
\text { Onde: } \\
p=\text { n. de dias em que houve ao menos um negócio com a ação no } \\
\text { período analisado } \\
P=\text { n. total de dias do período analisado } \\
n=\text { n. de negócios com a ação no período analisado } \\
N=\text { n. de negócios com todas as ações no período analisado } \\
v=\text { volume em dinheiro negociado com a ação no período analisado } \\
V=\text { volume em dinheiro negociado com todas as ações no período } \\
\text { analisado } \\
\text { preço/valor patrimonial das ação } \\
\text { estimado com base nos últimos } 12 \text { meses } \\
\text { Desvio-padrão dos retornos contínuos das ações } \\
\frac{P_{t+1}-P_{t}}{P_{t}} \text { onde, } P_{t+l}=\text { preço/VPA em } t+1 \\
\text { volume negociado em valores monetários } \\
\text { volume negociado/valor de mercado }\end{array}$} \\
\hline Lucro por ação & \\
\hline Liquidez el & \\
\hline Preço/VPA & \\
\hline Beta do Capm & \\
\hline Volatilidade (risco) & \\
\hline Retorno & \\
\hline Volume de negócios & \\
\hline Turnover & \\
\hline Estrutura de ca & \multirow{8}{*}{$\begin{array}{l}\text { passivo circulante + exigível a LP/patrimônio líquido } \\
\text { passivo circulante + passivo exigível a LP/ativo total } \\
\text { dívida de curto prazo/divída total } \\
\text { investimentos/patrimônio líquido } \\
\text { imobilizado/receita líquida operacional } \\
\text { variação percentual LPA/variação percentual LAJIR } \\
\text { variação percentual LAJIR/variação percentual das vendas }\end{array}$} \\
\hline Endividam & \\
\hline Endividamento do ativo & \\
\hline Endividamento de curto prazo & \\
\hline Financiamento $\mathrm{c}$ & \\
\hline Tangibilidade das operações & \\
\hline Alavancag & \\
\hline Alavancagem operacional & \\
\hline Controle & \multirow{4}{*}{$\begin{array}{l}\text { valor publicado no balanço patrimonial do respectivo ano, constante } \\
\text { do sistema de informações do Economática. } \\
\text { dados contábeis constantes dos demonstrativos dos resultados, } \\
\text { disponíveis no sistema de informações do Economática. } \\
\text { dividendos pagos por ação, constantes do sistema de informações do } \\
\text { Economática. }\end{array}$} \\
\hline Ativo total & \\
\hline Receita líquida & \\
\hline Payout & \\
\hline
\end{tabular}

Quadro 3 - Variáveis utilizadas no estudo

Os dados foram organizados com vistas a identificar o período de ocorrência ou não do efeito governança. O teste $t$ permite verificar a igualdade de médias de duas amostras emparelhadas, onde cada grupo é analisado duas vezes, antes e depois de um tratamento ou intervenção, formando pares de observações, cujas diferenças são testadas para verificar se o resultado é ou não zero (PESTANA; GAGEIRO, 2003). Assim, para avaliar a significância média das diferenças dos grupos antes e após os ingressos relativos ao período de 2001 a 2006, utilizou-se o teste $t$. A diferença das médias foi calculada conforme a equação:

$$
\Delta_{i}=\frac{\text { média }_{\text {depois }}-\text { média }_{\text {antes }}}{\text { média }_{\text {antes }}} \operatorname{com} i=1, \ldots \ldots, 27
$$

O período de relevância do efeito foi identificado também através do teste de Wilcoxon que, segundo Pestana e Gageiro (2003), é uma alternativa não paramétrica ao teste $t$ para amostras emparelhadas. O teste de Mann Witney é usado para testar as diferenças entre dois grupos, sendo uma alternativa útil para o teste paramétrico $t$ quando o tamanho amostral é pequeno (SIEGEL; CASTELLAN, 2006). Dessa forma, o teste foi aplicado para avaliar as 
diferenças nas variáveis de estrutura e desempenho, sendo os grupos definidos conforme a variável de governança corporativa. Para analisar a correlação entre as variáveis, adotou-se o coeficiente de correlação de Pearson.

Para avaliar se a governança corporativa influencia nas variações da estrutura de capital e no desempenho das empresas utilizou-se a técnica de análise de dados em painel. Segundo Biagni (2003, p. 75), "é um dos métodos mais usuais no meio acadêmico para se analisar os efeitos que algumas variáveis exercem, ou que parecem exercer, sobre outras". Marques (2000) completa esclarecendo que uma das vantagens da estimação com dados em painel é o tratamento da heterogeneidade dos dados.

Os dados em painel sugerem a existência de características diferenciadoras dos indivíduos, essas características podem ou não ser constantes ao longo do tempo, de tal forma que estudos temporais ou seccionais que não levem em conta tal heterogeneidade produzirão, quase sempre, resultados fortemente enviesados. Segundo Gujarati (2006), dados em painel, também chamados de dados combinados, mesclam séries temporais e cortes transversais em um único estudo, isto é, a mesma unidade de corte transversal é acompanhada ao longo do tempo. Para o autor a principal vantagem desta técnica é a obtenção de dados mais informativos, com mais variabilidade, menos colinearidade, mais graus de liberdade e mais eficiência.

Existem, basicamente, três formas de simplificar e ajustar o modelo geral a fim de torná-lo mais funcional: Modelo Pooled, Fixed-Effects Model (Efeitos Fixos) e o Random Effects (Efeitos Aleatórios). No primeiro modelo o intercepto é o mesmo para toda a amostra, ou seja, assume-se que todos os elementos da amostra possuem comportamento idêntico. $\mathrm{O}$ Modelo Pooled não considera o efeito do tempo e nem o efeito individual de cada empresa (BALTAGI, 2001 apud DAHER, 2004). Já o Modelo de Efeitos Fixos baseia-se na premissa de que os coeficientes da regressão podem variar de indivíduo para indivíduo ou no tempo, ainda que permaneçam como variáveis fixas, ou seja, não aleatórias (MARQUES, 2000). Por último, tem-se ainda o Modelo de Efeitos Aleatórios que segue a premissa de que a influência do comportamento do indivíduo ou o efeito do tempo não podem ser conhecidos. Dessa forma, admite-se a existência do erro não correlacionado com os regressores.

$\mathrm{Na}$ construção do modelo, primeiramente faz-se necessário verificar se as variáveis possuem associações lineares significativas. Se isto ocorrer, pode-se ter a frente o problema de multicolinearidade que será verificada através do cálculo dos Fatores de Inflacionamento da Variância (VIF), dado por $\operatorname{VIF}(j)=1 /\left(1-\mathrm{R}(j)^{\wedge} 2\right)$, onde $\mathrm{R}(j)$ é o coeficiente de correlação múltipla entre a variável $j$ e as outras variáveis independentes. Se o modelo estiver livre da multicolinearidade, a escolha entre os modelos poderá ser realizada através dos testes específicos.

Para a estimação dos modelos escolheu-se uma medida para cada aspecto, ou seja, o Retorno sobre o patrimônio líquido como representante do desempenho empresarial, o Retorno da ação como proxie para o desempenho de mercado e o Endividamento geral como medida da estrutura de capital. Como variáveis independentes relacionadas à governança tem se a independência do conselho, o índice de governança e o percentual de ações mantido pelos cinco maiores acionistas. Também foram incluídas como variáveis de controle a receita líquida e o payout. Os modelos estimados são os representados pelas equações 2,3 e 4 :

$\Delta \mathrm{ROE}=\beta_{1}+\beta_{2} \mathrm{ICON}_{i, t}+\beta_{3} \mathrm{IGOV}_{i, t}+\beta_{4} \Delta \mathrm{AC}_{5 \mathrm{M}_{i, t}}+\beta_{5} \Delta \mathrm{EG}_{i, t}+\beta_{6} \Delta \mathrm{LB}_{i, t}$ $+\beta_{7} \Delta \mathrm{RECL}_{i, t}+\beta_{8} \Delta \mathrm{PAYOUT}_{i, t}+\varepsilon_{1}$

$\Delta \mathrm{RET}=\beta_{1}+\beta_{2} \mathrm{ICON}_{i, t}+\beta_{3} \mathrm{IGOV}_{i, t}+\beta_{4} \Delta \mathrm{AC}_{5 \mathrm{M}_{i, t}}+\beta_{5} \Delta \mathrm{EG}_{i, t}+\beta_{6} \Delta \mathrm{LB}_{i, t}$ $+\beta_{7} \Delta \mathrm{RECL}_{i, t}+\beta_{8} \Delta \mathrm{PAYOUT}_{i, t} \beta_{9} \Delta \mathrm{BETA}_{i, t}+\varepsilon_{2}$ 
$\Delta \mathrm{EG}=\beta_{1}+\beta_{2} \mathrm{ICON}_{i, t}+\beta_{3} \mathrm{IGOV}_{i, t}+\beta_{4} \Delta \mathrm{AC} \mathrm{M}_{i, t}+\beta_{5} \Delta \mathrm{LB}_{i, t}+\beta_{6} \Delta \mathrm{RCL}_{i, t}$ $+\beta_{7} \Delta \mathrm{PAYOUT}_{i, t}+\beta_{8} \Delta \mathrm{BETA}_{i, t}+\varepsilon_{3}$

Onde, ROE é o retorno sobre o patrimônio líquido, RET é o retorno anual da ação, EG é o endividamento Geral, ICON é a indepência do conselho, IGOV é o índice de governança, AC5M é o percentual de ações mantido pelos cinco maiores acionistas, EG é o endividamento geral, LB é a liquidez em bolsa, RECL é a receita líquida, PAYOUT é o payout dos dividendos, BETA é o beta da ação. O símbolo $\Delta$ indica variação (valor em $t$ menos valor em $t$ - 1 dividido pelo valor em $t$ - 1 ).

\section{ANÁLISE DOS RESULTADOS}

O conteúdo do relatório de administração foi analisado conforme os itens obrigatórios de evidenciação segundo a Lei $n^{\circ}$ 6404/76, os recomendados pela Comissão de Valores Mobiliários (CVM) através do Parecer de Orientação $n^{\circ}$ 15/87 e algumas informações adicionais constantes da Lei ${ }^{\circ} 11.638 / 07$. A Tabela 1 apresenta os resultados dessa análise.

Tabela 1 - Variáveis de governança corporativa relacionadas ao relatório de administração do período de 2001 a 2006 das 84 empresas do nível 1, nível 2 e novo mercado da Bovespa

\begin{tabular}{l|c|c|c|c}
\hline \multicolumn{1}{c|}{ Variáveis } & \multicolumn{2}{c}{ Não divulga informação } & \multicolumn{2}{c}{ Divulga informação } \\
\cline { 2 - 5 } & Freqüência & Percentual & Freqüência & Percentual \\
\hline Emissão de debêntures & 50 & 59,50 & 34 & 40,50 \\
Reinvestimento de lucros e distribuição de & & & & \\
dividendos & 0 & 0,00 & 84 & 100,00 \\
Negócios sociais & 27 & 32,10 & 57 & 67,90 \\
Investimentos em coligadas e/ou controladas & 5 & 6,00 & 79 & 94,00 \\
Descrição dos negócios & 0 & 0,00 & 84 & 100,00 \\
Comentários sobre a conjuntura econômica & 14 & 16,70 & 70 & 83,30 \\
Recursos humanos & 14 & 16,70 & 70 & 83,30 \\
Investimentos realizados e a realizar & 4 & 4,80 & 80 & 95,20 \\
Pesquisa e desenvolvimento & 55 & 65,50 & 29 & 34,50 \\
Novos produtos e serviços & 11 & 13,10 & 73 & 86,90 \\
Meio ambiente & 36 & 42,90 & 48 & 57,10 \\
Reformulações administrativas & 22 & 26,20 & 62 & 73,80 \\
Direitos dos acionistas & 5 & 6,00 & 79 & 94,00 \\
Perspectivas futuras & 12 & 14,30 & 72 & 85,70 \\
Balanço social & 71 & 84,50 & 13 & 15,50 \\
Fluxo de caixa & 17 & 20,20 & 67 & 79,80 \\
Valor adicionado & 52 & 61,90 & 32 & 38,10 \\
Auditores independentes em consultoria & 28 & 33,30 & 56 & 66,70 \\
\hline Fonte: do
\end{tabular}

Fonte: dados da pesquisa.

Como esperado, pode-se constatar que todas as empresas analisadas divulgam os respectivos relatórios de administração no site da BOVESPA. Verificou-se que a política de distribuição e/ou reinvestimento de lucros, bem como a descrição dos negócios foram as únicas informações dispostas pela totalidade das empresas analisadas. Mais da metade dos relatórios revelou o envolvimento da empresa com alguma prática social e a utilização de auditores independentes em consultorias. Por outro lado, dentre as variáveis menos divulgadas, tem-se a emissão de debêntures e as relativas às informações adicionais, como o balanço social e a demonstração do valor adicionado (DVA). Pode-se conjecturar ainda que a não divulgação de informações sobre "pesquisa e desenvolvimento" possa ser uma política adotada pela empresa por tratar-se de uma área estratégica.

As variáveis constantes da Tabela 2 referem-se as demais variáveis de governança não 
nominadas na tabela anterior, cujos dados foram extraídos das informações anuais (IANs).

Tabela 2 - Variáveis de governança corporativa relacionadas às informações anuais do período 2001 a 2006 das 84 empresas do nível 1, nível 2 e novo mercado da Bovespa

\begin{tabular}{l|l|c|c}
\hline \multicolumn{1}{c|}{ Varíaveis } & \multicolumn{1}{c|}{ Categorias } & Frequência & Percentual \\
\hline Tipo de parecer & com ressalva & 7 & 8,30 \\
& sem resalva & 77 & 91,70 \\
\hline Auditoria & big five & 77 & 91,70 \\
& outras & 7 & 8,30 \\
\hline Tipo de controlador & um indivíduo & 2 & 2,40 \\
& mais de um indivíduo e/ou empresa & 72 & 85,70 \\
& sem controlador & 10 & 11,90 \\
\hline Acordo de acionistas & sim & 32 & 38,10 \\
& não & 52 & 61,90 \\
\hline Unificação de cargos & sim & 21 & 25,00 \\
& não & 63 & 75,00 \\
\hline
\end{tabular}

Observa-se um percentual significativo no que tange ao tipo de empresa de auditoria, sendo que $91,70 \%$ das empresas analisadas adotam como auditora uma das cinco pertencentes ao grupo das big five (Arthur Andersen, Ernst \& Young, Price WaterHouse Coopers, Deloitte Touche Tohmatsu e KPMG) e seus pareceres são geralmente sem ressalva. A unificação dos cargos no conselho de administração, ou seja, a mesma pessoa ocupando os cargos de diretor executivo e presidente do conselho ocorre em $25 \%$ dos casos, o que demonstra que a maioria das empresas analisadas separa os referidos cargos. Constata-se ainda a existência de empresas que não apresentam controlador nas informações anuais.

As 23 variáveis de governança, constantes das Tabelas 1 e 2, foram as utilizadas para a construção do índice definido no item 3 como uma das variáveis independentes na análise de regressão. Para avaliar se ocorreram alterações de estrutura e desempenho após a adesão aos níveis diferenciados de governança efetuou-se a análise das diferenças através dos testes $t$ de diferenças de médias e de Wilcoxon.

Em virtude da existência de assimetria positiva e distribuição leptocúrtica para a maioria das variações e do tamanho pequeno de alguns grupos optou-se por apresentar os resultados apenas do teste de Wilcoxon. As variações foram calculadas utilizando-se a fórmula (1) concentrando-se no período da variação.

$\mathrm{Na}$ Tabela 3 apresenta-se um panorama das variações ocorridas por variável e por período. As variáveis relativas à governança corporativa apresentaram decréscimo em suas medianas no segundo e terceiro ano. As variáveis liquidez geral, liquidez corrente, Q de Tobin, liquidez em bolsa e volume, como também, a receita líquida e o ativo total acusaram variações positivas em todos os períodos considerados. Na estrutura de capital, percebe-se que a variável tangibilidade das operações apresentou variações negativas em seis dos sete períodos estudados.

Noutro viés, verificou-se que, do total de 27 variáveis estudadas, 14 apresentaram variações no primeiro, segundo, terceiro e quinto ano. O quarto período apresentou variações em 13 variáveis. No sexto ano, 18 variáveis sofreram alterações e 11 variáveis se alteraram no sétimo ano. Tem-se ainda, o quinto e o sexto ano de adesão aos níveis de governança como os períodos que mais apresentaram melhorias nas variáveis consideradas no estudo.

A partir desta análise, buscou-se avaliar se cada uma das variáveis de governança nominais influencia nas variações obtidas para as variáveis de estrutura e desempenho. Assim, para cada variável, em todos os anos que as variações foram significativas, aplicou-se o teste de Mann-Whitney com o objetivo de avaliar se há diferenças entre as variações das empresas que aderiram a determinada prática de governança e aquelas que não aderiram. Os dados 
indicam uma baixa quantidade de variáveis com valores de significância inferiores e/ou igual a 0,05 , indicando que as diferenças das variações ocorreram não necessariamente pela adesão aos níveis de governança.

Tabela 3 - Freqüência das variações positivas (+) e negativas (-) com significância ao nível de $5 \%$ para as variáveis do primeiro ao sétimo ano

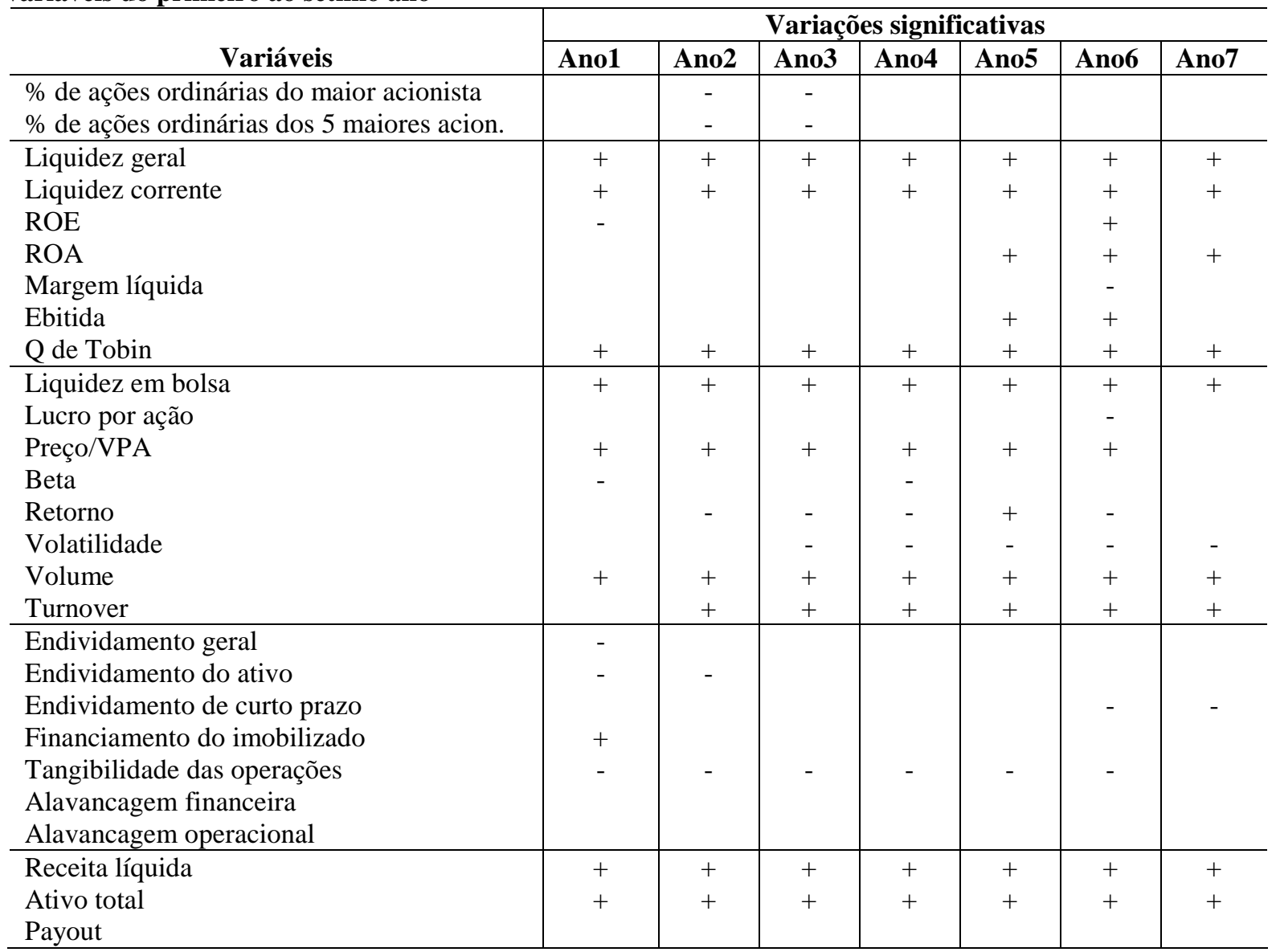

Fonte: dados da pesquisa.

Com o objetivo de verificar preliminarmente as relações entre as variáveis de governança e as variáveis de estrutura e desempenho foram analisados os coeficientes de correlação para uma avaliação inicial de possíveis problemas de multicolineariedade nos modelos de regressão a serem estimados. Tanto no primeiro, como no segundo ano, os valores de significância, em sua maioria superiores a 0,05, indicaram que não há correlação entre as variáveis de governança corporativa e as variáveis de desempenho e de estrutura de capital.

As estimativas iniciais dos três modelos (Pooled, Fixed-Effects e Random Effects) não indicaram diferenças significativas. Portanto, a fim de padronizar a interpretação dos resultados, optou-se por apresentar neste estudo todas as estimativas do modelo Pooled Regression. Na primeira tentativa de estimação, todos os modelos mostraram problemas de heterocedasticidade nos erros. Para resolver tal problema utilizou-se a estimativa robusta frente a problemas de heterocedasticidade nos erros (Heteroskedasticity Consistent -HC). Todos os valores do Fator de Inflação da Variância ficaram em torno de um caracterizando ausência de problemas de multicolineariedade.

$\mathrm{Na}$ Tabela 4 apresentam-se os coeficientes e suas respectivas significâncias, dos modelos estimados pelo método pooled regression, para as variações do retorno sobre o patrimônio líquido (ROE). 
Tabela 4 - Coeficiente, erro padrão, teste $t$ e p-valor do modelo Pooled Regression com erros padrão robustos (HC), para a variável dependende variação do Retorno sobre o Patrimônio Líquido

\begin{tabular}{lllll}
\hline Variáveis & coeficiente & erro padrão & teste $\boldsymbol{t}$ & p-valor \\
\hline Constante & $-0,426$ & 0,757 & $-0,563$ & 0,574 \\
ICON & 2,542 & 0,829 & 3,066 & 0,002 \\
IGOV & $-0,028$ & 0,014 & $-2,012$ & 0,045 \\
$\Delta$ AC5M & $-0,089$ & 0,434 & $-0,205$ & 0,838 \\
$\Delta$ EG & 1,046 & 0,350 & 2,990 & 0,003 \\
$\Delta$ LB & 0,001 & 0,000 & 0,516 & 0,606 \\
$\Delta$ RECL & 0,211 & 0,280 & 0,755 & 0,451 \\
$\Delta$ PAYOUT & 0,046 & 0,022 & 2,037 & 0,043 \\
\hline R-quadrado & 0,060 & R-quadrado ajustado & 0,040 \\
F(7, 328) & 4,039 & P-valor(F) & 0,000 \\
\hline Fon
\end{tabular}

Fonte: dados da pesquisa.

O modelo Pooled Regression apresentou quatro variáveis significativas. A proxies de governança corporativa, independência do conselho e índice de governança foram significativas, com destaque para o índice do conselho que apresentou o maior coeficiente. Dentre as variáveis de controle, foram significativas o endividamento geral e o payout. Portanto, variações positivas no endividamento e no payout influenciam positivamente as variações no retorno sobre o patrimônio líquido. Para avaliar o desempenho de mercado, a variável dependente escolhida foi o retorno anual. A Tabela 5 apresenta os resultados.

Tabela 5 - Coeficiente, erro padrão, teste $t$ e p-valor do modelo Pooled Regression com erros padrão robustos (HC), para a variável dependende variação do Retorno

\begin{tabular}{lllll}
\hline Variáveis & coeficiente & erro padrão & teste $\boldsymbol{t}$ & p-valor \\
\hline Constante & 3,102 & 1,215 & 2,552 & 0,011 \\
ICON & $-5,686$ & 1,428 & $-3,982$ & 0,000 \\
IGOV & 0,012 & 0,018 & 0,695 & 0,487 \\
$\Delta$ AC5M & 0,363 & 0,896 & 0,405 & 0,686 \\
$\Delta$ EG & $-0,848$ & 0,654 & $-1,297$ & 0,196 \\
$\Delta$ LB & 0,000 & 0,000 & $-1,779$ & 0,076 \\
$\Delta$ RECL & $-0,087$ & 0,299 & $-0,292$ & 0,771 \\
$\Delta$ PAYOUT & $-0,005$ & 0,020 & $-0,240$ & 0,811 \\
$\Delta$ BETA & $-0,019$ & 0,049 & $-0,386$ & 0,700 \\
\hline R-quadrado & 0,049 & R-quadrado ajustado & 0,026 \\
F(8, 327) & 3,874 & P-valor(F) & 0,000 \\
\hline
\end{tabular}

Verifica-se que, além da constante, apenas a variável independência do conselho foi significativa. Os valores negativos indicam que na medida em que aumenta a independência do conselho ocorre uma variação menor nos retornos das ações, ou seja, em média, empresas com conselhos mais independentes, após a entrada nos níveis de governança apresentaram menores variações nos retornos de suas ações.

Para o indicador de estrutura de capital, endividamento geral, os resultados obtidos foram os apresentados na Tabela 6 . Observa-se que, a independência do conselho novamente apresenta coeficiente negativo. A variação na concentração de ações nas mãos dos cinco maiores acionistas e a variação na liquidez em bolsa também são significativas.

Quando há uma diminuição na concentração acionária após a entrada nos níveis de governança, a variação é negativa e, portanto, o coeficiente positivo é coerente com o argumento teórico de que uma menor concentração acionária influencia positivamente a capacidade de endividamento da empresa. Espera-se que as empresas que adotaram melhores práticas de governança corporativa ganhem liquidez em bolsa (variação positiva), o que influencia favoravelmente sua capacidade de endividamento. 
Tabela 6 - Coeficiente, erro padrão, teste $t$ e p-valor do modelo Pooled Regression com erros padrão robustos (HC), para a variável dependende variação do Endividamento Geral

\begin{tabular}{lllll}
\hline Variáveis & coeficiente & erro padrão & teste $\boldsymbol{t}$ & p-valor \\
\hline Constante & 0,214 & 0,173 & 1,236 & 0,217 \\
ICON & $-0,337$ & 0,148 & $-2,272$ & 0,024 \\
IGOV & 0,000 & 0,002 & 0,155 & 0,877 \\
$\Delta$ AC5M & 0,365 & 0,135 & 2,698 & 0,007 \\
$\Delta$ LB & 0,001 & 0,000 & $-7,011$ & 0,000 \\
$\Delta$ RECL & $-0,018$ & 0,041 & $-0,435$ & 0,664 \\
$\Delta$ PAYOUT & 0,002 & 0,010 & 0,211 & 0,833 \\
$\Delta$ BETA & $-0,002$ & 0,006 & $-0,308$ & 0,758 \\
\hline R-quadrado & 0,040 & R-quadrado ajustado & & 0,020 \\
F(7, 328) & 13,965 & P-valor(F) & 0,000 \\
\hline
\end{tabular}

A análise dos coeficientes de determinação ajustados indica que as variáveis independentes acusam baixa influência nas variáveis dependentes, ou seja, há contribuição das variáveis independentes para a explicação dos modelos é muito pequena.

\section{CONCLUSÃO}

Esta pesquisa objetivou avaliar se a adoção das práticas de governança corporativa influencia a estrutura de capital e o desempenho das empresas. Para avaliar a governança, adotaram-se 27 variáveis. Destas, 23 foram obtidas a partir da análise de conteúdo dos relatórios de administração. Uma variável se refere à estrutura do conselho de administração (independência do conselho). A propriedade da empresa é avaliada a partir de três variáveis (percentual de ações do acionista controlador, percentual de ações do maior acionista e percentual de ações dos cinco maiores acionistas). O desempenho é considerado sob dois aspectos, variáveis atinentes à empresa e ao mercado. Na estrutura de capital, consideraram-se as variáveis referentes ao endividamento, adotando-se, ainda, o ativo da empresa, faturamento e pagamento de dividendos como variáveis de controle.

Por ocasião da identificação do período de ocorrência do efeito governança, os resultados do teste de Wilcoxon mostraram que nos dois primeiros anos de adesão (2001 e 2003), as variações de estrutura e desempenho foram significativas principalmente a partir do segundo ano de ingresso. Para as empresas que ingressaram nos demais anos, as variações, de maneira geral, ocorreram a partir do primeiro ano.

A partir da análise dos relatórios de administração pode-se observar que a grande maioria das empresas segue as normas previstas pela Lei $\mathrm{n}^{\circ} 6404 / 76$, pela Comissão de Valores Mobiliários e as constantes da Lei $\mathrm{n}^{0} 11.638 / 07$, indicando a presença de práticas de governança corporativa.

$\mathrm{Na}$ análise das variações anuais, com relação as variáveis de desempenho da empresa, observa-se que variações positivas ocorreram principalmente para a liquidez geral e corrente, e para o Q de Tobin. Para o desempenho de mercado, os acréscimos mais significativos foram obtidos em termos de liquidez, medida pelo volume e pela liquidez em bolsa. Tais resultados sugerem que, ao ingressar nos níveis de governança corporativa, as empresas consigam melhorar sua imagem no mercado, atraindo investidores e conseqüentemente obtendo ganhos de liquidez. Já em termos de risco, observa-se que, na maioria dos casos, as alterações no beta não são significativas e, em termos de retorno, na maioria dos anos não há ganhos significativos. Com relação à estrutura de capital, destaca-se a variável tangibilidade das operações, que na maioria dos períodos apresentou variações negativas. Por outro lado, parece não haver grandes alterações em termos de alavancagem e endividamento.

Ao separar as empresas que adotam as práticas de governança daquelas que não 
adotam, a partir da aplicação do teste de Mann-Mitney observou-se que poucas variáveis apresentaram diferenças significativas, sugerindo que as variações de desempenho e estrutura de capital, podem não ter ocorrido em consequiência da adesão aos níveis de governança.

Do mesmo modo, os modelos de regressão em painel estimados apresentaram baixo valor de explicação e poucas variáveis significativas. Dentre as variáveis significativas cabe destacar a independência do conselho. Como argumenta Silveira (2002), a aparente independência do conselho das companhias brasileiras deve ser questionada. Apesar da questão legal que obriga um máximo de um terço de membros internos, geralmente os membros externos são conselheiros indicados pelo acionista controlador para representar seus interesses e não por conselheiros profissionais sem vínculo com a companhia. Neste sentido, Dutra e Saito (2002) mostram que 49\% dos conselheiros das empresas brasilerias são representantes do controlador e apenas $21 \%$ são conselheiros profissionais.

Em síntese, os resultados obtidos mostram que as empresas que aderiram ao N1, N2 e NM no período estudado estão desencadeando esforços para adoção de práticas de governança, pelo menos as sugeridas pelas normativas. No entanto, as melhorias de estrutura de capital e desempenho observadas são pouco influenciadas pela adoção de tais práticas. Contudo, não se pode descartar a possibilidade de ocorrência de outros ganhos, como por exemplo, a melhoria da imagem da empresa perante os agentes financeiros e ao próprio mercado de capitais.

Uma das limitações da pesquisa é a escolha das variáveis utilizadas. Optou-se por aquelas que melhor se aproximaram do objeto da análise, entretanto, é muito difícil uma aproximação perfeita. Além disso, há de se considerar a especificação do modelo, ou seja, a escolha das variáveis independentes, da variável dependente e de controle. Estudos vindouros podem aprimorar esta pesquisa, acrescentando outras variáveis, não só melhorando as definições daquelas já adotadas, como também utilizando novas técnicas estatísticas com aplicação do modelo de equações simultâneas, contribuindo assim, para a ampliação e melhoria dos estudos que envolvem a gestão corporativa brasileira.

\section{REFERÊNCIAS}

ANDRADE, G. R. de. Estudo econométrico dos efeitos da migração para OIGC: índice de ações com governança corporativa diferenciada da Bovespa. Internext - Revista Eletrônica de Negócios Internacionais, São Paulo, v. 3, n. 1, p. 39-53, jan./jun. 2008.

ANTUNES, G. A.; COSTA, F. M. Governança e qualidade da informação contábil: uma investigação utilizando empresas brasileiras que aderiram ou não aos níveis diferenciados de governança da BOVESPA. In: ENCONTRO DA ASSOCIAÇÃO NACIONAL DE PÓSGRADUAÇÃO E PESQUISA EM ADMINISTRAÇÃO (ENANPAD), 31., 2007, Rio de Janeiro. Anais... Rio de Janeiro: ANPAD, 2007.

ASSAF NETO, A. Estrutura e análise de balanços. São Paulo: Atlas, 2000.

BALTAGI, B. H. Econometric analysis of panel data. 2 ed. England: John Wiley, 2001.

BAYESINGER, B.; BUTLER, H. Corporate governance and the board of directors: performance effects of changes in board composition. Journal of Law, Economics and Weisbach Organization, Oxford University Press, v.1, p.101-124, 1985.

BHAGAT, S.; BLACK, B. The uncertain relationship between board composition and firm performance. Business Lawyer, Chicago, v. 54, p.921-963, 1999.

BIAGNI, F. L. Fatores determinantes da estrutura de capital das empresas de capital aberto no Brasil: uma análise em painel. 2003. Dissertação (Mestrado em Administração) Pontifícia Universidade Católica do Rio de Janeiro. Rio de Janeiro, PUC/RJ, 2003. 
BOVESPA. Folheto informativo: Novo Mercado e níveis diferenciados de governança, 2007. Disponível em: <http://www.bovespa.org.br>. Acesso em: 14 jan. 2008.

BRASIL. Lei ${ }^{\circ}$ 6404, Lei das Sociedades por Ações, de 15 de dezembro de 1976. Dispõe sobre as sociedades por ações. In: Manuais de Legislação Atlas. 6. ed. São Paulo: Atlas, 1999. v. 28.

Lei $\mathrm{n}^{\circ} 11.638$, de 28 de dezembro de 2007. Altera e revoga dispositivos da Lei $\mathrm{n}^{\circ}$ 6.404, de 15 de dezembro de 1976, e da Lei $\mathrm{n}^{\circ}$ 6.385, de 7 de dezembro de 1976, e estende às sociedades de grande porte disposições relativas à elaboração e divulgação de demonstrações financeiras. Diário Oficial [da] República Federativa do Brasil, Brasília, DF, 28 dez. 2007. Disponível em: <http://www.planalto.gov.br/ccivil 03/ato2007 2010/2007/Lei/L11638.htm>. Acesso em: 25 dez. 2008.

BUSHMAN, R.; SMITH, A. Financial accounting information and corporate governance.The Jornal of Accounting and Economics, n. 32, p. 237-333, 2001. doi:10.1016/S01654101(01)00027-1

CABRAL, A. S.; CAMARGO, L. F. T.; HOLMO, R. Z.; LOURES, P. L.; SILVA JR., A. F. A. Estudo de caso sobre o perfil das estruturas de capital e rentabilidade de indústrias brasileiras. In: ENCONTRO NACIONAL DE ENGENHARIA DE PRODUÇÃO (ENEGEP), 23., 2003, Ouro Preto. Anais... São Paulo: ABEPRO, 2003.

CARLSSON, R. Ownership and value creation: strategic corporate governance in the new economy. New York: John Wiley \& Sons, 2001.

CARVAlHO, A. G. Governança corporativa no Brasil em perspectiva. Revista de Administração, São Paulo, v. 37, n. 3, p. 19-32, jul./set. 2002.

CATAPAN, A.; CATAPAN, E.A. Rentabilidade e endividamento do setor elétrico brasileiro: um enfoque sobre sustentabilidade organizacional. In: ENCONTRO NACIONAL DE ENGENHARIA DE PRODUÇÃO (ENEGEP), 26., 2006, Fortaleza. Anais... São Paulo: ABEPRO, 2006.

COMISSÃO DE VALORES MOBILIÁRIOS. Folheto informativo, 2007. Disponível em: <http//www.cvm.gov.br>. Acesso em: 14 jan. 2008.

COMISSÃO DE VALORES MOBILIÁRIOS. Parecer de Orientação CVM n ${ }^{\circ} \mathbf{1 5}$, de 28 de dezembro de 1987. Procedimentos a serem observados pelas companhias abertas e auditores independentes na elaboração e publicação das demonstrações financeiras, do relatório de administração e do parecer de auditoria relativos aos exercíicos sociais encerrados a partir de dezembro de 1987. Disponível em: 〈http://www.cvm.gov.br>. Acesso em: 29 set. 2008.

COPELAND, T.; KOLlER, T.; MURRIN, J. Avaliação de empresas. Tradução de Maria Cláudia S. R. Ratto. 2. ed. São Paulo: Makron Books, 2000.

CORRAR, L. J.; PAULO, E.; FILHO J. M. D. (Orgs.). Análise multivariada. São Paulo: Atlas, 2007.

DAHER, C. E. Testes empíricos de teorias alternativas sobre a determinação da estrutura de capital das empresas brasileiras. 2004. Dissertação (Mestrado em Administração) Universidade de Brasília, Brasília, 2004.

DALFIOR, V.A.O.; OLIVEIRA, V.G.R.S.; SOUZA, C.A. Adoção de práticas de governança corporativa e análise econômico-financeira em bancos. Revista Brasileira de Contabilidade, Brasília, nº 167, set./out. 2007.

DAMI, A. B. T.; ROGERS, P.; RIBEIRO, K. C. S. Estrutura de propriedade no Brasil: 
evidências empíricas no grau de concentração acionária. Contextus. Revista Contemporânea de Economia e Gestão, Universidade Federal do Ceará, v. 5, n. 2, jul./dez. 2007.

FAMA, E.; JANSEN, M. Separation of ownership and control. Journal of Law and Economics, University of Chicago Press, Jun, 1983.

GALDI, F.C.; MENEZES, R.M. Estrutura de propriedade e as relações com o valor e desempenho das empresas brasileiras. In: CONGRESSO USP DE CONTROLADORIA E CONTABILIDADE, 10., 2010, São Paulo. Anais... São Paulo, 2010.

GALLON, A. V.; BEUREN, I. M. Análise da relação entre evidenciação nos relatórios da administração e o nível de governança das empresas na Bovespa. In: ENCONTRO DA ASSOCIAÇÃO NACIONAL DE PÓS-GRADUAÇÃO E PESQUISA EM ADMINISTRAÇÃO (ENANPAD), 30., 2006, Salvador. Anais... Rio de Janeiro: ANPAD, 2006.

GOMPERS, P.; ISHII, J.; METRICK, A. Corporate governance and equity prices. Quarterly Journal of Economics, v.118, n.1, p. 107-155, 2003. doi:10.1162/00335530360535162

GUJARATI, D. Econometria básica. Rio de Janeiro: Elsevier, 2006.

HERMALIN, B.; WEISBACH, M. Boards of directors as an endogenously determined institution: a survey of the economic literature. NBER working paper n. 8161, Cambridge, Massachusetts, 2001.

IQUIAPAZA, A. R.; TOMAZ, W. P.; AMARAL, H. F. Governança corporativa e divulgação de relatórios financeiros anuais. In: ENCONTRO NACIONAL DOS CURSOS DE GRADUAÇÃO EM ADMINISTRAÇÃO (ENANGRAD), 18., 2007, Cuiabá. Anais... São Paulo: ANGRAD, 2007.

MALACRITA, M. J. C.; YAMAMOTO, M. M. Governança corporativa: nível de evidenciação das informações e sua relação com a volatilidade das ações do Ibovespa. In: ENCONTRO DA ASSOCIAÇÃO NACIONAL DE PÓS-GRADUAÇÃ̃ E PESQUISA EM ADMINISTRAÇÃO (ENANPAD), 29., 2005, Brasília. Anais... Brasília: 2005.

MARQUES, L. D. Modelos dinâmicos com dados em painel: revisão de literatura. Dissertação (Mestrado em Economia) - Faculdade de Economia do Porto, Portugal, 2000.

MARTINS, V. A.; SILVA, R. L. M.; NARDI, P. C. C. Governança corporativa e liquidez das ações. In: ENCONTRO DA ASSOCIAÇÃO NACIONAL DE PÓS-GRADUAÇÃO E PESQUISA EM ADMINISTRAÇÃO (ENANPAD), 30., 2006, Salvador. Anais... Rio de Janeiro: ANPAD, 2006.

NASCIMENTO, A. M.; BIANCHI, M.; TERRA, P. R. S. A Controladoria como um mecanismo interno de governança corporativa: evidência de uma survey comparativa entre empresas de capital brasileiro e norte-americano. In: CONGRESSO BRASILEIRO DE CUSTOS, 12., 2005, Itapema/SC. Anais... São Leopoldo: ABC, 2005.

PAVODEZE, C. L; BENEDICTO, G. C. Análise das demonstrações financeiras. São Paulo: Pioneira Thomson Learning, 2005.

PESTANA, M. H; GAGEIRO, J. N. Análise de dados para ciências sociais. 3. ed. Lisboa: Sílabo, 2003.

PROCIANOY, J. L; SCHNORRENBERGER, A. A influência da estrutura de controle nas decisões de estrutura de capital das companhias brasileiras. In: ENCONTRO BRASILEIRO DE FINANÇAS, (SBFIN), 2., 2002, Rio de Janeiro. Anais... Rio de Janeiro, SBFIN, 2002. 
RAMOS, G. M.; MARTINEZ, A. L. Governança corporativa e gerenciamento de resultados contábeis. In: ENCONTRO DA ASSOCIAÇÃO NACIONAL DE PÓS-GRADUAÇÃO E PESQUISA EM ADMINISTRAÇÃO (ENANPAD), 30., 2006, Salvador. Anais... Rio de Janeiro: ANPAD, 2006.

ROGERS, P.; RIBEIRO, K. C. S.; SOUZA, A. F. Determinantes macroeconômicos da governança corporativa no Brasil. In: ENCONTRO DA ASSOCIAÇÃO NACIONAL DE PÓS-GRADUAÇÃO E PESQUISA EM ADMINISTRAÇÃO (ENANPAD), 30., 2006, Salvador. Anais... Rio de Janeiro: ANPAD, 2006.

ROSS S. A.; WESTERFIELD, R. W; JAFFE, J. F. Administração financeira: corporate finance. 2. ed. São Paulo: Atlas, 2007.

SHLEIFER, A.; VISHNY, R. Asurvey of corporate governance. Journal of Finance, v. 52, n. 2, p. 737-783, 1997. doi:10.2307/2329497

SIEGEL, S.; CASTELLAN JÚNIOR, N. Estatística não paramétrica para ciências do comportamento. 2. ed. Porto Alegre: Bookman, 2006.

SILVA, W. M; MORAES, W. F. A. Punidos por baixo desempenho: impactos da governança corporativa sobre o turnover de executivos no Brasil. Revista Organizações e Sociedade, v. 13, n. 36, p. 125-143, 2006. Disponível em: <http://www.revistaoes.ufba.br/index.php>. Acesso em: 12 mai. 2008.

SILVEIRA, A. M. Governança corporativa, desempenho e valor da empresa no Brasil. 2000. 165f. Dissertação (Mestrado em Administração) - Faculdade de Economia, Administração e Contabilidade, Universidade de São Paulo, São Paulo, 2002.

SILVEIRA, A. M.; BARROS, L. A. B. C.; FAMÁ, R. Qualidade da governança corporativa influencia o valor das companhias abertas no Brasil? In: ENCONTRO DA ASSOCIAÇÃO NACIONAL DE PÓS-GRADUAÇÃO E PESQUISA EM ADMINISTRAÇÃO (ENANPAD), 29., 2005, Brasília. Anais... Rio de Janeiro: ANPAD, 2005.

SLOAN, R. Financial accounting and corporate governance: a discussion. Journal of Accounting and Economics. n. 32, p. 335-347, 2001. doi:10.1016/S0165-4101(01)00039-8

WAGNER, J.; STEMPERT, L.; FUBARA, E. Board composition and organizational performance: two studies of insider/outsider effects. Journal of Management Studies, Oxford, v.35, p. 655-677, 1998. doi:10.1111/1467-6486.00114 